\title{
IMPLEMENTATION OF AN INTEGRATED SYSTEM OF INTERMITTENT HEAT SUPPLY FOR EDUCATIONAL INSTITUTIONS
}

\author{
Oleksandr Klymchuk \\ Department of Thermal Powel Plants and energy saving technologies \\ Odessa National Polytechnic University \\ 1 Shevchenko ave., Odessa, Ukraine, 65044 \\ ak@ctk.center \\ Alla Denysova \\ Department of Thermal Powel Plants and energy saving technologies \\ Odessa National Polytechnic University \\ 1 Shevchenko ave., Odessa, Ukraine, 65044 \\ alladenysova@gmail.com \\ Gennadiy Balasanian \\ Department of Thermal Powel Plants and energy saving technologies \\ Odessa National Polytechnic University \\ 1 Shevchenko ave., Odessa, Ukraine, 65044 \\ balasanyan@opu.ua \\ Alhemiri Saad Aldin \\ Department of Thermal Powel Plants and energy saving technologies \\ Odessa National Polytechnic University \\ 1 Shevchenko ave., Odessa, Ukraine, 65044 \\ saadaldin@outlook.com \\ Krystyna Borysenko \\ Department of Water Supply \\ Odessa State Academy of Civil Engineering and Architecture \\ 1 Shevchenko ave., Odessa, Ukraine, 65044 \\ nefertichtvo@ukr.net
}

\footnotetext{
Abstract

A review of the current world state of application of various heat supply regimes for public buildings is conducted. The efficiency analysis of the use of various renewable energy sources in combined heat supply systems is analyzed. An integrated heat supply system with successive heating of the coolant from low-potential renewable sources of heat (solar system) to high-temperature traditional heat sources (gas and pellet boilers) is developed. A mathematical model of the integrated heat supply system using renewable sources of heat is proposed. This model can be used to simulate the processes of heating rooms in the intermittent heat supply mode.

The dynamics of heating of premises with various heating devices: with natural convection (radiator) and forced convection (fan coils) is carried out. During the heating season (2016-2017), the operation modes of integrated systems of alternative intermittent heat supply (ISAIHS) are studied.

These studies are extremely relevant for solving the issues of rational use of energy resources. The proposed solutions show that the most effective use of renewable sources of heat can be only in an integrated approach to solving this issue. Also it should be noted the interaction of ISAIHS components: the heat source - the heating system - the characteristics of the building - the operating modes of the premises.

As a result of the research, the boundaries of the effective use of various heat generators in ISAHS are established. The influence of the type of heating devices and insulation of internal walls on the effectiveness of ISAIHS operation is revealed. The full-scale tests of a pilot installation of an integrated heat supply system are carried out.
} 
The obtained results will help to use heat sources more efficiently with a two-period operation regime for new houses. This can be used to improve the energy efficiency of existing buildings.

Keywords: integrated heat supply system, heat pump, intermittent heating, operation mode of the building.

\section{Introduction}

In accordance with the Law of Ukraine on priority directions for the development of science and technology [1], the main direction of the state policy of Ukraine in the field of energy conservation is the creation of a highly efficient energy supply structure. This is realized through a comprehensive solution of energy saving issues taking into account environmental requirements [2].

The analysis of theoretical and experimental studies shows that when only $10 \%$ of consumers in the southern regions of Ukraine are transferred to alternative heat supply, annual fuel savings (0170000 mln $\mathrm{t}$ f.e.) can be achieved [3]. With the use of insolation, the average annual capacity of $4300 \mathrm{MJ} / \mathrm{m}^{2}$ can provide about $25 \%$ of the consumers' needs for heating and $50 \%$ for hot water supply [4]. According to world forecasts, by 2020 the share of heat pumps using renewable energy sources (RES) for heating purposes will reach $75 \%$ [5]. Practical implementation of integrated power supply systems based on the heat pump cycle is of considerable interest for energy-saving technologies [6]. So, theoretical and practical research aimed at increasing the efficiency of integrated energy supply systems by adapting them to changing energy consumption regimes and optimizing the processes of heat storage [7].

It should be noted that to accelerate the process of practical implementation of heat supply systems using alternative fuels, it is necessary to reduce the payback period by increasing the replacement rate of traditional primary energy carriers [8]. For heat supply systems operating in the constant supply mode, this problem can only be solved by replacing the possibilities of renewable energy sources (RES) is problematic [9].

Currently, the municipal economy of the world uses a large number of administrative buildings, which do not require the maintenance of a constant mode of heating. For example, educational facilities of universities, colleges, schools, kindergartens, administrative buildings. These institutions during the non-working period do not require constant heat [10].

Energy savings based on environmental requirements can be obtained by implementing integrated systems of autonomous heat supply for intermittent heat supply (ISAIHS). These systems have the rational use of traditional, renewable energy sources and energy alternatives on alternative fuels.

It is necessary to use heat accumulators in ISAIHS, they are able to accumulate energy during non-working period. This contributes to the harmonization of energy generation and consumption schedules [11] due to the optimal organization of the power supply regime using combined thermal insulation [12]. The optimization criterion is the maximum share of replacement of organic fuel.

The urgency of the work is that justifying the conditions for implementing the proposed intermittent heat supply system leads to significant energy savings. In addition, ISAIHS is a rational way to improve the operating conditions of the system by eliminating pulsations during heat generation.

\section{Literature review and problem statement}

The issue of increasing the efficiency of heat for the use of various heat generators [13], operating in the integrated heat supply system (IHSS) is given great attention [14-16]. But there is no theoretical information, confirmed experimentally, on the effectiveness of an integrated system of autonomous heat supply, which operates in the mode of intermittent heat supply (ISAIHS) [15]. There is also no information on the operation of this system, taking into account the operating conditions of the building [16].

It should be noted that the ISAIHS intermittent operating mode, according to the schedule of the working process, depends on the duration of the period of heat generation during the day that is 
a function of the outside air temperature. At the same time, the basic heat generator is a heat pump, and the pellet boiler is used for peak room heating at low outside air temperatures.

Simulation of ISAIHS dynamic properties is performed for the conditions of the educational institution. The system operates in intermittent heating mode using elements such as: heat pump, pellet boiler and accumulator tank [12]. At the same time, the heat pump is connected in parallel with the pellet boilers. To match the temperature regimes and operating pressures in the heat pump circuit and the heating system, a separation heat exchanger is installed.

The equation for determining the optimal daily mode of ISAIHS, when the objective function of the heat load is minimal, is:

$$
\sum_{\mathrm{i}=0}^{23} \mathrm{Q}_{\mathrm{i}}=\sum_{\mathrm{i}=0}^{23}\left(\mathrm{Q}_{\mathrm{i}}^{\mathrm{hb}}+\mathrm{Q}_{\mathrm{i}}^{\mathrm{hp}}\right),
$$

where $\mathrm{i}$ - the time of day, $\mathrm{h} ; \mathrm{Q}_{\mathrm{i}}^{\mathrm{hb}}$ - hourly average heat capacity of the boiler, $\mathrm{kW} ; \mathrm{Q}_{\mathrm{i}}^{\mathrm{hp}}$ - hourly average heat capacity of heat pump, $\mathrm{kW}$

From the mathematical point of view, the optimization problem can be considered as the problem of finding the extremum of a function of several variables. 24 variable values $\left(Q_{i}^{\mathrm{hb}}, \mathrm{Q}_{\mathrm{i}}^{\mathrm{hp}}\right.$, $\mathrm{i}=\overline{0,23}$ ) are used, which correspond to the average hourly heat loads. The problem is solved taking into account the constraints and boundary conditions imposed on the system.

Taking into account the nature of the dependence between the variables, the optimization problem belongs to the class of nonlinear programming problems and in general form has the form:

$$
\left\{\begin{array}{c}
\sum_{\mathrm{i}=0}^{23} \mathrm{Q}_{\mathrm{i}}=\sum_{\mathrm{i}=0}^{23}\left(\mathrm{Q}_{\mathrm{i}}^{\mathrm{hb}}+\mathrm{Q}_{\mathrm{i}}^{\mathrm{hp}}\right) \rightarrow \min , \\
\left\{\begin{array}{l}
\mathrm{Q}_{\mathrm{i} \min } \leq \mathrm{Q}_{\mathrm{i}}^{\mathrm{hb}} \leq \mathrm{Q}_{\mathrm{i} \max }, \\
\mathrm{Q}_{\mathrm{i} \min }^{\mathrm{hp}} \leq \mathrm{Q}_{\mathrm{i}}^{\mathrm{hp}} \leq \mathrm{Q}_{\mathrm{i} \max }^{\mathrm{hp}}, \\
\mathrm{i}=\overline{0,23 .}
\end{array}\right.
\end{array}\right.
$$

At the same time, the operation of the integrated heat supply system must be coordinated with the operation of the main consumer - the heating system, if take into account, in turn, the operating modes of the building.

Currently, intermittent operation of heat supply systems has received a lot of attention. A mathematical model is widely known [17], which is based on the heat balance equation using quasi-stationary approximations [18].

If use the notations used in the theory of automatic control, the differential equation for the temperature of the internal air in the room is written as follows:

$$
\begin{gathered}
\mathrm{T}_{\mathrm{B}} \frac{\mathrm{dt}_{\hat{A}}}{\mathrm{~d} \tau}+\mathrm{t}_{\mathrm{B}}=\mathrm{kW}_{0}+\mathrm{T}_{\mathrm{H}} \frac{\mathrm{dt}_{\mathrm{H}}}{\mathrm{d} \tau}+\mathrm{t}_{\mathrm{H}}, \\
\mathrm{T}_{\mathrm{B}}=\frac{\operatorname{c\rho F} \delta}{\mathrm{q}_{0} \mathrm{~V}}\left(\frac{\delta}{2 \mathrm{R} \lambda}+\frac{1}{\alpha_{\mathrm{H}} \mathrm{R}}\right),
\end{gathered}
$$

where $\mathrm{T}_{\mathrm{H}}$ - the time constant of differentiation for the outside air temperature, in this case, in deriving the equation, it turned out that $\mathrm{T}_{\mathrm{B}}=\mathrm{T}_{\mathrm{H}}$, 
$k=1 /\left(\mathrm{q}_{0} V\right)-$ the transmission coefficient for "heating system power - internal air temperature" channel.

To assess the effect of heat accumulation [19] on the efficiency of intermittent heating, a simplified mathematical model of a building [20] consisting of an outer fence and internal partitions is considered.

External fences and partitions are considered as elements with lumped parameters, have known thermal resistances and capacities.

Based on the carried out studies, it is possible to choose the type of the optimal heat management law (Fig. 1).

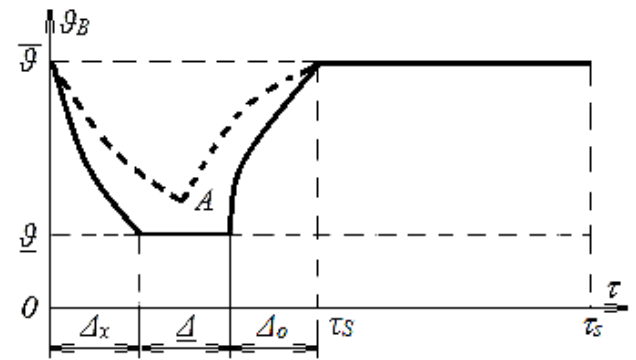

Fig. 1. The graph of the change in air temperature during intermittent heating during the day: $\bar{\vartheta}$ - the temperature in the room under operating conditions; $\vartheta$ - the temperature in the room during standby mode; $\tau_{s}$ - the time of the start of the operating mode; $\tau_{s}-$ the end time of the operating mode; $\Delta_{x}$ - cooling period of the room; $\underline{\Delta}$ - the period of the standby mode; $\Delta_{\mathrm{o}}-$ the overheat period; point $\mathrm{A}$ - transition from the cooling period to the over-night period without reaching the standby mode

On the graph (Fig. 1), the interval of switching of the heating modes $\tau_{\mathrm{S}}$ is divided into sub-intervals of durations $\Delta_{\mathrm{x}}, \underline{\Delta}, \Delta_{\mathrm{o}}$ - ensuring the minimum permissible temperature and overheat, respectively. For periods of system operation in intermittent mode $\Delta_{\mathrm{x}}, \underline{\Delta}, \Delta_{\mathrm{o}}$ affect both external and internal factors. So when the outside temperature decreases, the periods $\Delta_{\mathrm{x}}, \Delta_{\mathrm{o}}$ will grow, and the period $\Delta$ will decrease until it becomes zero and no point $A$ appears $-\mathrm{a}$ transition to the over-current mode without reaching the operating mode. On the other hand, the more the inertia of a building, the more periods of cooling and overheat will be, and the less will be the period of the standby mode.

The analysis of the sources shows [17-19] that the choice of heat supply modes for combined systems and the efficiency of renewable sources of heat depends not only on climatic conditions, but also on the operating conditions of the building (primarily from the functional purpose of the building). The developed models allow the use of intermittent modes of heat supply, but do not fully reflect the relationship of the heat supply system. For example, the efficiency of the operating modes of heat generators with a heating system for various heating appliances, incl. with natural and forced convection. Based on known results, it is necessary to carry out studies of the efficiency of the complex heat generator-heating system - the dynamic properties of the building.

\section{The aim and objectives of research}

The aim of research is a scientific and technical justification and definition of the conditions for the effective introduction of a new class of integrated alternative heat supply system (ISAIHS) operating in the intermittent heating mode with the realization of the possibility of energy storage. This will increase the efficiency of using heat generators and reduce the nominal power of energy sources.

Achieving this aim requires the following tasks:

- development of the thermal scheme of the ISAIHS model, operating in the intermittent heating mode taking into account the temperature regimes of heat consumers and climatic conditions;

- development of a mathematical model of ISAIHS operating modes and justification of the choice of rational operating conditions with regard to the operating conditions of the building; 
- rational choice of heating appliances that affects the efficiency of the system;

- study of the efficiency of thermal processes in ISAIHS and constituent elements, taking into account the specific features of the heat pump, various sources of renewable energy sources, heat accumulator, combined thermal insulation of walls and other factors depending on climatic conditions.

\section{Materials and methods of research}

The solution of the tasks is carried out by the method of numerical simulation and experimental studies of processes on the proposed scheme of combined heat supply, as well as by the study of the dynamics of room heating.

A peculiarity of the experimental ISAIHS is that the heat sources are connected in series with respect to the heat carrier of the heating system (Fig. 2). In this case, low-potential alternative heat generators (solar collectors and heat pump) are contained at the beginning of the coolant circulation circuit, that is, the most remote from the heat point. This allows first to use the maximum achievable technical potential of renewable energy in variable climatic conditions. And then, in case of a shortage of RES technical capabilities (daily, weekly, seasonal), connect high-potential reserve energy sources (condensing boilers and/or boilers on biofuel).

It should be noted that the use of the above-mentioned layout of the thermal scheme of the ISAIHS pilot facility makes it possible to prevent the conditions for the occurrence of so-called "temperature blocking" through the "underutilization" of the achievable potential of RES. Thermal locking is a negative heat effect as a result of inefficient use of all RES possibilities. For example, when it is premature to use a standby energy source (hot water boiler). This arrangement prevents the suppression of the low-potential circuit of the system circulation by high-temperature parameters of the gas and pellet boiler circuit.

Thus, more rational inclusion of sources of heat generation is ensured - a sequence of stepwise temperature increase from a low-temperature to a high-temperature source.

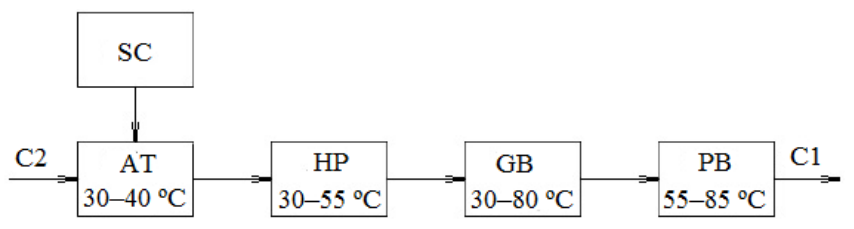

Fig. 2. A scheme for the sequential transfer of heat from various sources of energy:

$\mathrm{C} 1$ - coolant in the supply line; $\mathrm{C} 2$ - coolant in the return line; $\mathrm{SC}$ - solar collector;

AT - accumulator tank; HP - heat pump; GB - gas boiler; PB - pellet boiler

The proposed ISAIHS is implemented in the educational building of the Odessa National Polytechnic University. Constructive characteristics of the educational building as a heat supply facility:

4 floors, thickness of the walls $-0.6 \mathrm{~m}$, area of the inner walls $-1500 \mathrm{~m}^{2}$, volume of premises $-4800 \mathrm{~m}^{3}$, heated area $-1200 \mathrm{~m}^{2}$.

The circuit-design and thermal characteristics of the heating system:

- two-pipe system with an individual heat point of Danfoss. Adjusting the water temperature with correction for the temperature of the indoor air.

- the heat output of the heating system at a design ambient temperature $-70 \mathrm{~kW}$.

As part of ISAIHS, the main generators of heat are used: $18.5 \mathrm{~kW}$;

- an air-to-water heat pump of Viessmann-Vitocal 350-A, (Germany), with a capacity of

- gas hot water boilers of Viessmann, Vitodens 200, Vitopend 100, Vitodens 222 (Germany), with a total heat output of $80 \mathrm{~kW}$;

- pellet boiler of Heiztechnik (Germany) with a heating capacity of $30 \mathrm{~kW}$.

Experimental studies of the ISAIHS pilot installation are carried out during 2016-2017 provided that the working temperature is maintained in the premises from 8 am to $3 \mathrm{pm}$. On weekends, the room was maintained at a regular temperature. The basic heat load is borne by the 
heat pump, the double boiler is a pellet boiler. A gas boiler covers a lack of heat at low outside temperatures.

\section{Results of a pilot study of the ISAIHS effectiveness}

During the heating period (November-March), an experimental study of ISAIHS performance was conducted. Each heat source operated in an effective temperature range (Fig. 2). Based on the results of the studies, a generalized schedule of the ISAIHS operation has been constructed taking into account the climatic conditions (Fig. 3).

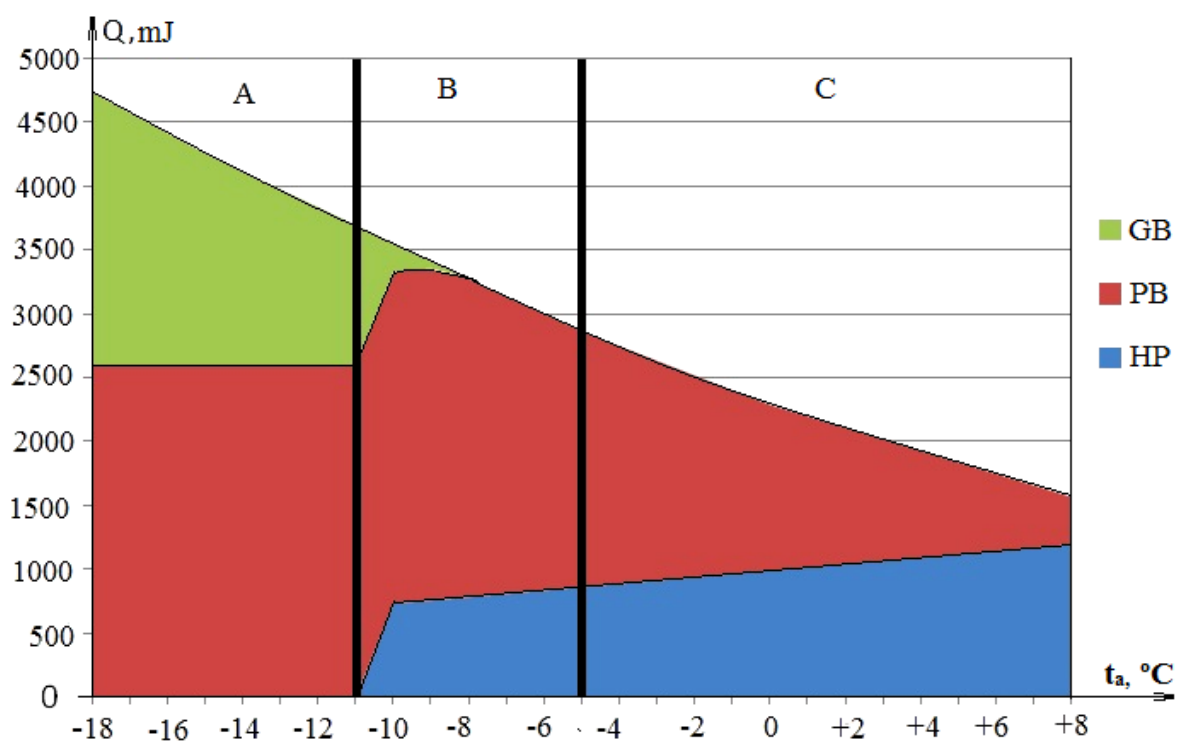

Fig. 3. Generalizing schedule of heat generation by different ISAIHS sources in the heating season when the climatic conditions change: A - the boiler operation area; B - the HP operation for heating the coolant in the return line, $\mathrm{C}$ - the zone of HP full-scale operation in the energy-efficient zone, GB - gas boiler; PB - pellet boiler; HP - heat pump

Based on the results of the analysis of the studies, the following conclusions can be drawn. The share of heat from solar collectors in the heating season is very low. For most of the period, two sources of heat work in the heat supply system. The total capacity of the two sources (GB+PB) is able to provide the necessary amount of heat to the training building, which indicates the uselessness in the application of each source with a calculated capacity. This allows significantly reduce investment in the combined heat supply system.

This allows to divide the HP operation in the ISAIHS into three zones:

A - HP operation in the ISAIHS outside the energy-efficient zone $(\mathrm{COP}<2)$;

$\mathrm{B}$ - HP operation in the ISAIHS as the first degree of heating of the coolant from the return line with subsequent heating in the boilers (PB, GB);

$\mathrm{C}-\mathrm{HP}$ operation on the full heating of the ISAIHS coolant.

To determine the effectiveness of the application in the intermittent heat supply of various heating systems, a number of experiments were conducted in the educational building of ONPU. The experiment was carried out by switching on/off the heating system of the building of the educational building with two types of heating systems with natural convection (radiator heating) (Fig. 4) and forced convection (fan coils) (Fig. 5).

Due to the limited possibility of conducting a full-scale experiment for all TTL building rooms simultaneously, the tests were carried out separately in several standard rooms: room 15 (corner room, 1st floor, $32 \mathrm{~m}^{2}$ area, $600 \mathrm{~mm}$ brick walls, $100 \mathrm{~mm}$ polystyrene foam, glazing ratio $=0,3$ ), room 22 (the room is in the middle of the building, the 2 nd floor is $60 \mathrm{~m}^{2}$, the walls are $600 \mathrm{~mm}$ brick, glazing ratio $=0,7)$. 


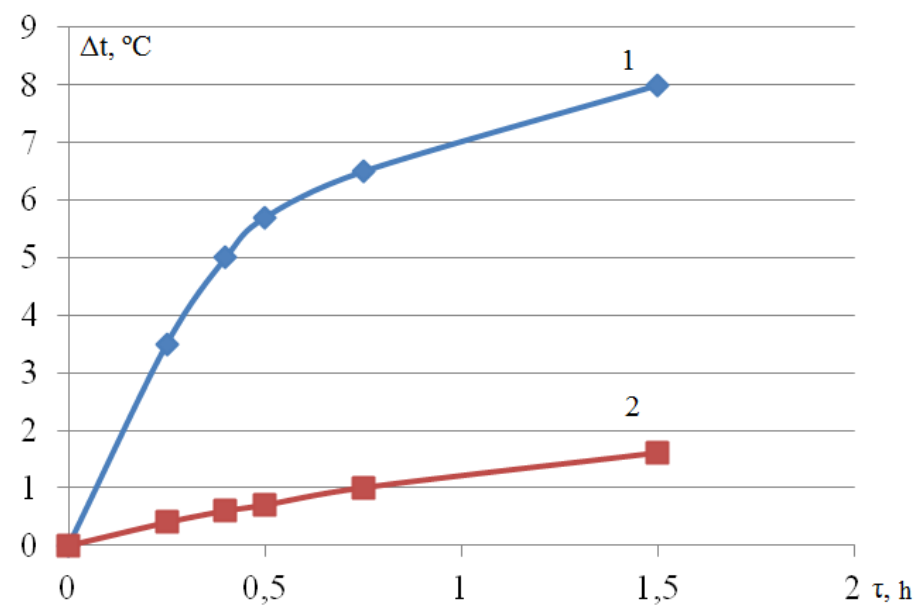

Fig. 4. Dynamics of room 22 heating: 1 - using a fan coil; 2 - using a radiator

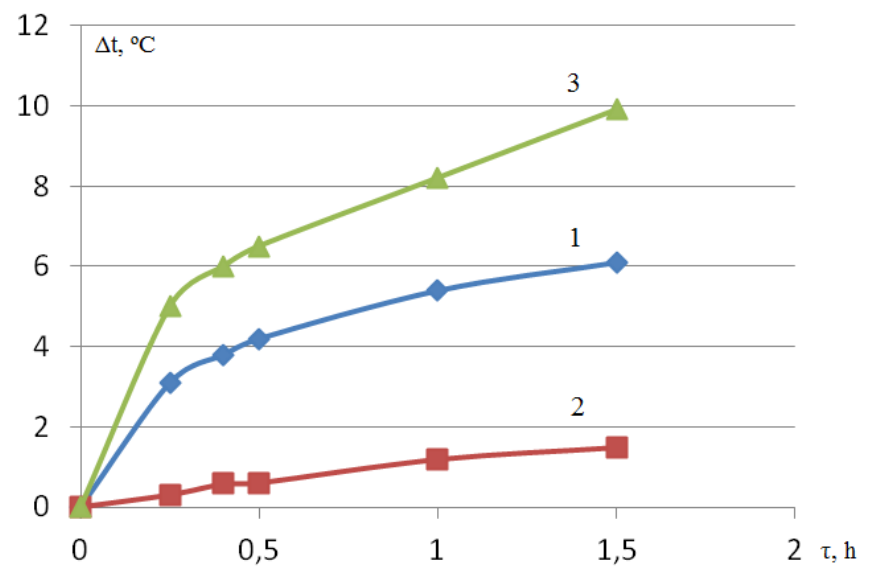

Fig. 5. Dynamics of room 15 heating: 1 - using a fan coil; 2 - using a radiator; 3 - using a fan coil for partial insulation

As can be seen from the research results, the use of air heating with the help of local fan coil devices allows to significantly accelerate the process of heating the premises with the use of a two-period operation mode. In this case, the insulation of internal walls allows to speed up the over-the-top mode at least twice.

This circumstance makes it possible to significantly reduce the cost of heating the premises of the educational building due to the later inclusion of a heating system for classrooms.

\section{Conclusions}

1. ISAIHS thermal scheme is proposed. It provides a rational sequence of heat transfer from various sources of energy. This allows to prevent the phenomenon of "temperature blocking" from underutilization of the achievable technical potential of renewable energy taking into account climatic factors. Thus, this arrangement prevents the suppression of the low-potential circuit of the system circulation by high temperature parameters of the GB circuit. The proposed solution allows to increase the percentage of using the heat of the outside air to $20 \%$.

2. Analysis of the mathematical model of ISAIHS operation modes allows to justify the duration of the heating mode taking into account the operation mode of the building. The choice of heat supply modes for combined systems and the efficiency of renewable heat sources depend not only on climatic conditions, but also on the operating conditions of the building (primarily from the functional purpose of the building). Is the interval of the switching of the heating modes of the heating system set to the sub-intervals of the durations? $\Delta_{x}, \Delta, \Delta_{0}$ - cooling, ensuring the minimum permissible temperature and overheat, respectively. For periods of system operation in intermittent 
mode $\Delta_{\mathrm{x}}, \Delta, \Delta_{\mathrm{o}}$ affect both external and internal factors. So when the outside temperature decreases, the periods $\Delta_{\mathrm{x}}, \Delta_{\mathrm{o}}$ will grow, and the period $\Delta$ will decrease until it becomes zero and no point $\mathrm{A}$ appears - a transition to the over-current mode without reaching the operating mode. On the other hand, the more the inertia of a building, the more periods of cooling and overheat will be, and the less will be the period of the standby mode.

3. Experimental studies have shown that the use of fan coils as heating devices improves the efficiency of intermittent heat supply in comparison with radiator heating. This allows to accelerate the time to enter the operating mode at least four times, which can significantly reduce the period of over-flooding.

4. Based on the results of the analysis of the studies, the following conclusions can be drawn. The share of heat from the solar system in the heating season is too low. For the most part of the period, two heat sources $(\mathrm{HP}+\mathrm{PB}$ and $\mathrm{PB}+\mathrm{GB})$ operate in the heat supply system. The total capacity of the two sources $(\mathrm{GB}+\mathrm{PB})$ is able to provide the necessary amount of heat to the training building, which indicates the uselessness in the application of each source with a calculated capacity. This allows significantly reduce investment in the combined heat supply system. At the same time, the heat output of the heat pump is calculated to compensate for the thermal losses to the outside air temperature from $-5{ }^{\circ} \mathrm{C}$ or higher. At the same time, a pellet boiler is used for the overheat mode. The total number of solar collectors is calculated based on the possibility of location on the roof.

\section{References}

[1] Pro prioritetni napryamki rozvutku nauki i tehniki (2001). Verkhovna Rada Ukrainy, No. 2623-III. Available at: http://zakon0.rada.gov.ua/laws/show/2623-14

[2] Zakon Ukrainy pro enerhozberezhennia: 74/94 vid 1.07.1994 r. (1994). Zakony Ukrainy, 7, 281-291.

[3] Denysova, A. E., Bodnar, I. A., Denysova, A. S. (2015). Heat pump using subsoil waters as low temperature heat source. Problemele energeticii regionale termoenergetica, 2 (28), 67-75.

[4] Denysova, A. E., Mazurenko, A. S., Denysova, A. S. (2016). Installation of potable water supply and heat supply at base of subsoil water. Renewable Energy and Environmental Sustainability, 1, 43. Available at: http://www.rees-journal.org/articles/rees/pdf/2016/01/rees160046-s.pdf doi: 10.1051/rees/2016046

[5] Renewable energy in Europe (2016). Recent growth and knock-on effects. European Environment Agency. Report, 4, 73.

[6] Guelpa, E., Barbero, G., Sciacovelli, A., Verda, V. (2017). Peak-shaving in district heating systems through optimal management of the thermal request of buildings. Energy, 137, 706-714. doi: 10.1016/ j.energy.2017.06.107

[7] Mazurenko, A., Denysova, A., Balasanian, G., Klimchuk, A., Borysenko, K. (2017). Improving the operation modes efficiency in heat pump systems of hot water supply with the two-stage heat accumulation. Eastern-European Journal of Enterprise Technologies, 1 (8 (85)), 27-33. doi: 10.15587/1729-4061.2017.92495

[8] Chwieduk, D. (2014). Solar energy in buildings. Academic Press, 4, 352.

[9] Ziemele, J., Gravelsins, A., Blumberga, A., Blumberga, D. (2017). Sustainability of heat energy tariff in district heating system: Statistic and dynamic methodologies. Energy, 137, 834-845. doi: 10.1016/ j.energy.2017.04.130

[10] Schweiger, G., Rantzer, J., Ericsson, K., Lauenburg, P. (2017). The potential of power-to-heat in Swedish district heating systems. Energy, 137, 661-669. doi: 10.1016/j.energy.2017.02.075

[11] Li, J., Fang, J., Zeng, Q., Chen, Z. (2016). Optimal operation of the integrated electrical and heating systems to accommodate the intermittent renewable sources. Applied Energy, 167, 244-254. doi: 10.1016/j.apenergy.2015.10.054

[12] Balasanian, G. A., Minyalo, M. B., Klymchuk, A. A. (2015). Modelirovanie rezima prerivistogo otoplenie kombinirovanie sistemi teplosnabzenia s teplovim nasosom. Vestnik NTU "HPI", 17, 97-102. 
[13] Denysova, A. E., Mazurenko, A. S., Denysova, A. S. (2014). Efficiency of multi-module solar collectors as the prefix to the boiler. Journal of theAcademy of Sciences of Moldova "Problemele energeticii regionale. Seria Termoenergetica", 3 (26), 53-59.

[14] Liubarets, O., Borisenko, K., Domoshchey, T., Zaitsev, O. (2017). Particular Systems for Periodic Heating of Tourist Complexes. Ventyliatsiia, osvitlennia ta teplohazopostachannia, 22, 21-25

[15] Nagornaya, A. N. (2008). Matematicheskoe modelirovanie i issledovanie nestacionarnogo teplovogo rezima zdaniy. Chelyabinsk, 150.

[16] Sokolov, V. Y., Mitrofanov, S. V., Sadchikov, A. V. (2016). Energosberezenie v systemah zizneobespecheniya. Novosybirsk: Izd. "SibAK", 178.

[17] Panferov, V. I., Anisimova, E. Y. (2008). Analiz vozmoznosti ekonomii teplovoy energii pri prerivistom rezime otoplenia. Vestnik YUrGU. Seria "Stroitelstvo i arkhitektura", 6 (12), 30-37.

[18] Klimchyk, O. A. (2017). Kompleksnyi pidkhid do rishennia pytan pidvyshchennia efektyvnosti system teplopostachannia v zakladakh osvity. Informatsiini tekhnolohii: nauka, tekhnika, tekhnolohiia, osvita, zdorov‘ya. (MicroCAD-2017). Kharkiv: NTU «KhPI», 32.

[19] Kucenko, A. C., Kovalenko, S. V., Tovaznianskiy, V. I. (2014). Analiz energoeffektivnosti preryvistogo rezhima otopleniya zdaniya. Polzunovskiy vestnik, 1 (4), 247-253.

[20] Vasiliev, G. P., Lichman, V. A., Peskov, N. V. (2010). Chislenniy metod optimizacii prerivistogo rezima otoplenia. Matematicheskoe modelirovanie, 22 (11), 123-130. 